DOI: 10.20472/IAC.2017.032.013

PUI LING FUNG

The Open University of Hong Kong, Hong Kong

\title{
FACTORS INFLUENCING THE SUPERVISORY RELATIONSHIP FROM THE CLINICAL MENTORS' PERSPECTIVE
}

\begin{abstract}
:
Supervisory relationship is essential to mentoring in clinical placement. Literature reported that supervisory relationship between clinical mentors and nursing students may affect the process of mentoring. The purpose of this study is to the factors influencing the supervisory relationship from clinical mentors' perspective in Hong Kong.

Methodology

The explorative qualitative study design was adopted in this study. Eight clinical mentors from the hospitals and nursing institution in Hong Kong were recruited. Semi-structured interviews were conducted. Data analysis was conducted. Several themes were identified
\end{abstract}

\section{Findings}

The supervisory relationship was influenced by several factors which included the engagement, the format of the placement, attitude toward students and impression of the students.

The clinical mentors engaged in the supervisory relationship through increased interaction such as greeting and actively approach the students. The level of engagement could be affected by the format of the clinical placement. The clinical mentors may be able to have more time to interact with a student during individual mentoring. The time for interaction with students decreased when the number of students mentored increased.

The attitude toward students may affect the supervisory relationship. The clinical mentors who treated students as a team member had a better supervisory relationship. The clinical mentors showed empathy to the students when they worked with the students as a team. It promoted the student's sense of belonging and enhanced the supervisory relationship.

The supervisory relationship was also influenced by the impression of the students. The impression of the students could be affected by their appearance and their behaviour. It may influence the interaction between the clinical mentors and the nursing students.

\section{Conclusion}

The findings of this study are important in improving the current practice in managing the supervisory relationship. It could help the clinical mentors to manage the supervisory relationship better. The nursing educators and management of the clinical setting could also adjust the arrangement of clinical placement and enhance the mentor training.

\section{Keywords:}

Supervisory relationship, clinical education, nursing education 